\title{
Mesolimbic dopamine transients in motivated behaviors: focus on maternal behavior
}

\author{
Donita L. Robinson ${ }^{1,2,3}$ *, Dawnya L. Zitzman ${ }^{1}$ and Sarah K. Williams ${ }^{2,3}$ \\ 'Bowles Center for Alcohol Studies, University of North Carolina, Chapel Hill, NC, USA \\ 2 Department of Psychiatry, University of North Carolina, Chapel Hill, NC, USA \\ ${ }^{3}$ Curriculum in Neurobiology, University of North Carolina, Chapel Hill, NC, USA
}

\section{Edited by:}

Sheryl Moy, University of North

Carolina, USA

\section{Reviewed by:}

Yolanda Mateo, National Institute on Alcohol Abuse and Alcoholism, USA George V. Rebec, Indiana University, USA

Leslie Sombers, North Carolina State University, USA

\section{*Correspondence:}

Donita L. Robinson, Center for Alcohol Studies, University of North Carolina, CB \#7178, Chapel Hill, NC 27599-7178, USA.

e-mail:dlr@unc.edu
Phasic activity of the mesolimbic dopamine pathway - burst-firing of dopamine neurons and the resulting dopamine release events at striatal targets - have been associated with a variety of motivational events, such as novelty, salient stimuli, social interaction, and reward prediction. Over the past decade, advances in electrochemical techniques have allowed measurement of naturally occurring dopamine release events, or dopamine transients, in awake animals during ongoing behavior. Thus, a growing body of studies has revealed dynamic dopamine input to ventral striatum during motivated behavior in a variety of experimental paradigms. We propose that dopamine transients may be important neural signals in pup-directed aspects of maternal behavior, as preliminary data suggest that dopamine transients in dams are associated with pup cues. Measurements of dopamine transients may be useful to investigate not only typical maternal behavior but also maternal inattention induced by drug exposure or stress.

Keywords: dopamine, phasic, voltammetry, in vivo, maternal, social, reward
Dopamine exerts considerable influence on animal behavior. In addition to the control of voluntary movement (e.g., Parkinson's disease), dopamine plays an important role in reward and motivation (preliminary data: Ikemoto and Panksepp, 1999; Salamone et al., 2005, 2007; Alcaro et al., 2007). Thus, it is central not only to many natural behaviors, such as reproduction and ingestion, but also to pathologic ones, like addiction and other compulsive disorders. Telencephalic dopamine projections arise from the ventral tegmental area (VTA) and the substantia nigra in the midbrain and ascend to multiple forebrain structures, most notably the caudate, putamen, and nucleus accumbens (NAc; collectively called the striatum). All of these projections have been implicated in various aspects of motivated behavior. For example, nigral dopaminergic afferents to the dorsolateral striatum participate in habit-learning and automatic responses to cues, while those to the dorsomedial striatum have been implicated in goal-directed behaviors and action selection (Yin and Knowlton, 2006; Wickens et al., 2007; Lovinger, 2010; de Wit et al., 2011). Furthermore, the dopaminergic system most closely associated with cue-reward associations is the mesolimbic pathway, projecting from the VTA in the midbrain to anterior targets that include the NAc, olfactory tubercle, and prefrontal cortex. This review will focus on the mesolimbic dopamine system as it is the dopamine projection most studied in the context of maternal behavior. Nevertheless, dopaminergic input to each striatal region is likely to play important roles in maternal behavior.

By using in vivo neurochemical methods, many studies have demonstrated that extracellular dopamine concentrations in the NAc increase in the minutes to hours during natural reward such as

Abbreviations: FSCV, fast scan cyclic voltammetry; MPOA, medial preoptic area; NAc, nucleus accumbens; VTA, ventral tegmental area. sex and food, during stress, or following administration of addictive drugs (for review, see Westerink, 1995; Phillips et al., 2008; Willuhn et al., 2010). More recent research suggests that one aspect of dopamine release - fast fluctuations in dopamine called dopamine transients - is a neural correlate of reward salience, approach initiation, and learning (for review, see Robinson et al., 2008; Willuhn et al., 2010). As such, mesolimbic dopamine transients may be a useful window on reward processing in maternal behavior. The goal of this review is to describe the expression of dopamine transients during behavior in studies to date and consider how these fast dopamine events can instruct us on the dopaminergic contribution to both normal and disrupted maternal behavior.

\section{DOPAMINE TRANSIENTS AS A WINDOW INTO REWARD AND REINFORCEMENT PROCESSING}

Much of what we have learned of extracellular dopamine dynamics has been dependent on the neurochemical methods to measure them in vivo. Microdialysis (Westerink, 1995; Watson et al., 2006) has been used to successfully measure dopamine in various terminal regions. Because the diffusion-based technique has limited ability to track dynamic concentration changes, it is best suited for monitoring slow (over minutes) changes in dopamine concentrations over broad $(\mathrm{mm})$ areas of tissue. Microdialysis research has yielded a wealth of information about dopamine levels during a range of motivated behaviors, including maternal behavior. For example, dopamine levels rise in the NAc during active maternal behaviors, such as nursing and licking pups (Hansen et al., 1993). However, microdialysis lacks the resolution to observe brief changes in dopamine that result from burst-firing of dopamine neurons and are time-locked to specific behavioral events or environmental stimuli (Borland et al., 2005; Yang and Michael, 2007). In contrast, fast scan cyclic voltammetry (FSCV, Box 1) is used to measure 
A

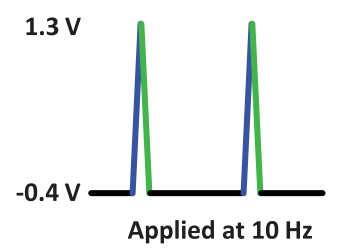

B

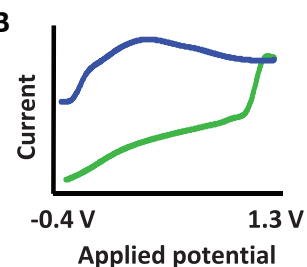

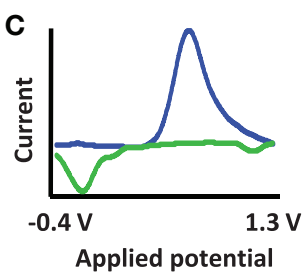

D
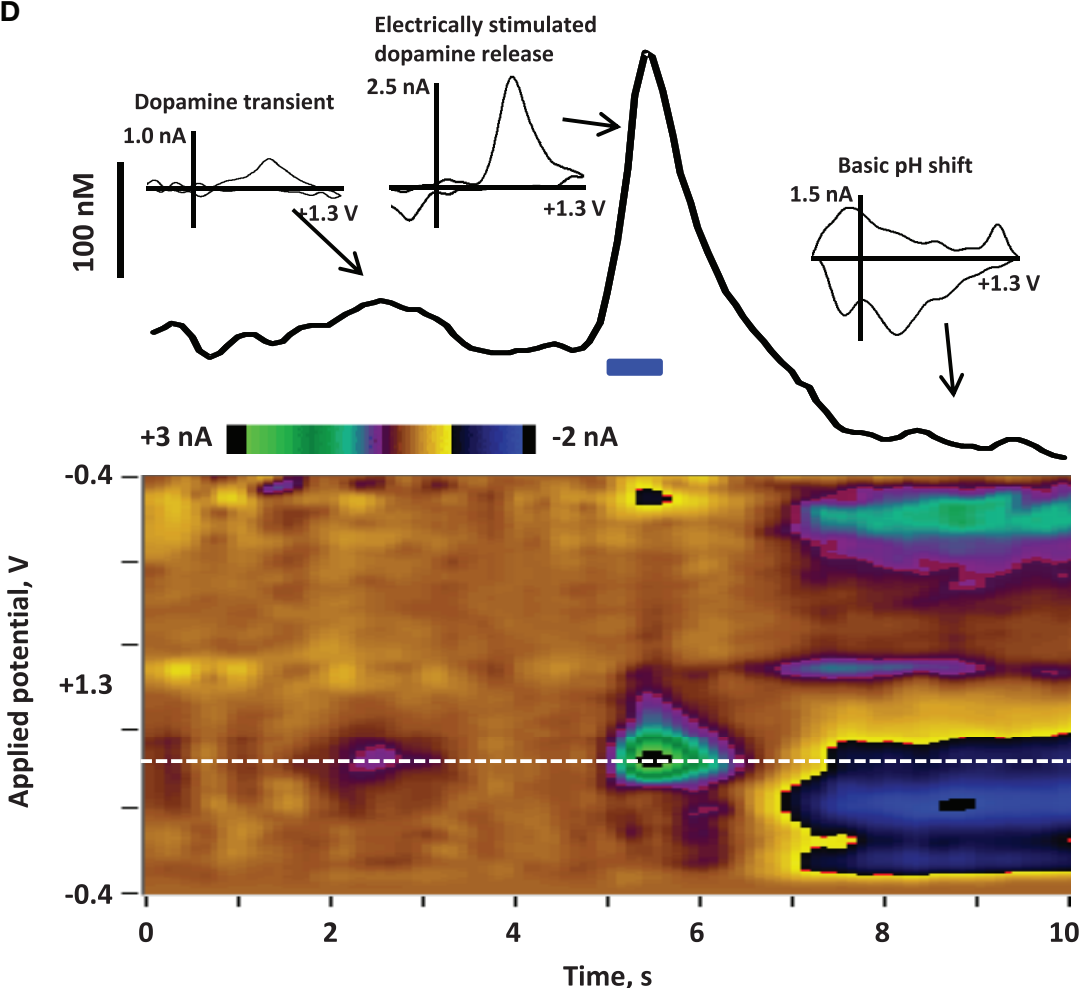

BOX 1 | Fast scan cyclic voltammetry (FSCV) to detect dopamine release

FSCV is a method used to electrochemically detect dopamine in situ at the surface of a carbon-fiber microelectrode (Robinson et al., 2008). First, a potential is applied to the electrode; the triangle waveform shown in (A) is typically used for electrochemical detection of extracellular dopamine in freely moving rats. This waveform ramps from -0.4 to $+1.3 \mathrm{~V}$ and back, applied at $400 \mathrm{~V} / \mathrm{s}$ and repeated at $10 \mathrm{~Hz}$. The precise parameters of the applied waveform (such as the range of potentials, the shape of the waveform, and the speed and frequency at which it is applied) will vary depending on the analyte. Next, current is detected at the electrode due to redox reactions on the electrode surface as well as charging of the double layer around the electrode. This current is depicted in the cyclic voltammogram in (B) current associated with the positive, oxidative sweep of the applied waveform is in blue, while current at the negative, reductive sweep is in green. The charging current is large but stable over short time frames ( 60 s); thus, the charging current can be subtracted to reveal smaller currents associated with fast changes, such as the oxidation and reduction of dopamine release depicted in (C) (background-subtracted cyclic voltammogram of dopamine; oxidation in blue, reduction in green). Importantly, analyte selectivity is obtained by choosing waveform parameters that yield distinguishing background-subtracted cyclic voltammograms for the analyte versus other biological compounds (Robinson and Wightman, 2007). (D) Illustrates electrically evoked dopamine release in an awake rat recorded by using FSCV. Current detected at the electrode across time is depicted in a color plot to visualize changes in current at the range of applied potentials (Michael et al., 1998); potential is on the $y$-axis, time is on the $x$-axis and current is in color). To better illustrate changes in dopamine, the current at the oxidation potential of dopamine (white dotted line, approximately $+0.6 \mathrm{~V}$ versus an $\mathrm{Ag} / \mathrm{AgCl}$ reference electrode) is shown in the trace above the color plot. Dopamine neurons in the midbrain were stimulated with a bipolar electrode (indicated by the blue bar at $5 \mathrm{~s} ; 40 \mathrm{~Hz}, 16 \mathrm{p}$, biphasic, $2 \mathrm{~ms} /$ phase, $120 \mu \mathrm{A}$ ) and the resulting dopamine release in the nucleus accumbens is observed by increased oxidative current. By calibrating the electrode after the experiment (Logman et al., 2000), current can be converted to dopamine concentration to estimate the amount of dopamine release ( $250 \mathrm{nM})$. This change in current can be confirmed as dopaminergic by evaluation of the cyclic voltammogram (inset). Such electrical stimulation is often followed by basic changes in $\mathrm{pH}$ (Kawagoe et al., 1992; Venton et al., 2003; Takmakov et al., 2010), as is observed by the negative current at the oxidative sweep and positive current at the reductive sweep in 7-10 s; the cyclic voltammogram (inset) associated with this change in $\mathrm{pH}$ is clearly distinguished from dopamine. FSCV can also be used to detect spontaneous dopamine release events, or dopamine transients. A small transient is observed between 2 and $3 \mathrm{~s}$, identified by the cyclic voltammogram (inset). 
these fast and often sub-second, dopamine fluctuations due to the temporal $(100 \mathrm{~ms})$ and spatial (typically $100 \mu \mathrm{m})$ resolution of the method.

Extracellular dopamine concentrations can be considered within the framework of tonic and phasic release. Tonic dopamine concentrations arise from the population activity of dopamine neurons innervating a target region. While estimates of basal, tonic dopamine levels in striatum range from 5 to $100 \mathrm{nM}$ (Ross, 1991; Kawagoe et al., 1992; Suaud-Chagny et al., 1992; Justice, 1993), these concentrations are likely sufficient to occupy dopamine autoreceptors and high-affinity postsynaptic receptors (Richfield et al., 1989). This "tone" at the dopamine receptors is thought to be important to facilitate movement and gate a variety of dopamine-dependent behaviors (Berke and Hyman, 2000). Furthermore, mesolimbic dopamine tone is an important regulator of effort that an animal will expend to obtain a reward (Salamone et al., 2005). Phasic, burst-firing of dopamine neurons, on the other hand, produces dopamine transients (Kawagoe et al., 1992; Suaud-Chagny et al., 1995; Garris and Rebec, 2002; Sombers et al., 2009): brief, higher concentrations of dopamine that may activate low-affinity dopamine receptors. These phasic dopamine signals are important, for example, for cue-associated learning about reward and salient stimuli (Schultz, 1998; Tsai et al., 2009; Zweifel et al., 2009). Moreover, these brief bursts of firing and the resulting dopamine transients are thought to be important in behavioral switching (Redgrave et al., 1999). Interestingly, dopamine terminals in the ventral striatum appear to corelease glutamate upon phasic firing, which adds another dimension to the function of dopamine transients (Sulzer and Rayport, 2000; Lapish et al., 2006; Hnasko et al., 2010; Stuber et al., 2010a; Tecuapetla et al., 2010). Specifically, the addition of a time-locked glutamatergic signal may provide a transient the true ability to time-lock to stimuli and reward because glutamate activates fast ligand-coupled ion channels. In contrast, postsynaptic dopamine actions via G-protein coupled receptors are slower and may modulate postsynaptic responses to converging inputs (Lapish et al., 2006). Nevertheless, although the complex molecular signaling interactions are still under investigation, it is clear that dopamine transients play a critical contributory role in learning about and appropriate responding to the environment.

Thus, tonic and phasic dopamine firing and release are thought to have distinct receptor targets and different functions in the behaving animal (Garris and Rebec, 2002; Schultz, 2007; Hauber, 2010). In light of this duality, it is important to note that microdialysis and FSCV provide complementary measurements of dopamine dynamics; for example, increases in the number of dopamine neurons that are spontaneously active influence the tonic dopamine concentrations measured with microdialysis (Floresco et al., 2003), whereas increases in dopamine burst-firing do not necessarily affect measurements of dopamine tone (Lu et al., 1998; Floresco et al., 2003; Borland et al., 2005). In contrast, FSCV detects variation in dopamine transient rates that reflect burst rates of dopamine neurons (Sombers et al., 2009), but the method has limited utility to detect slower changes in extracellular dopamine concentrations (Robinson et al., 2008). It is interesting that while the general role of dopamine in maternal behavior is well established and associated with a rise in tonic dopamine levels (Numan, 2007; Stolzenberg and Numan, 2011), little is known of phasic dopamine activity during maternal behavior.

Transient increases in firing rate, or burst-firing, of dopamine neurons have been recorded in many animal models at numerous events, such as salient environmental stimuli (experimenter hand approach, whisker touch) and reward delivery (for review, see Overton and Clark, 1997). Perhaps the most iconic illustration of phasic dopamine activity during reward processing comes from experiments by Wolfram Schultz and colleagues (Schultz et al., 1997; Schultz, 1998). Recording from midbrain dopamine neurons in primates during a simple Pavlovian task, they found that dopaminergic neurons briefly increased firing rate in response to an unexpected squirt of juice (reward). However, when the animal learned that a cue predicted the reward, the phasic dopamine activity shifted from the reward delivery to the presentation of the conditioned cue. Since FSCV instrumentation and techniques advanced to the point that they could be used in freely moving rats, dopamine transients have been measured at these same events: salient environmental stimuli, reward delivery, and conditioned cues (for review, see Robinson et al., 2008). One advantage of measuring dopamine release as opposed to neuronal firing rate is that while electrophysiology reveals firing patterns of individual neurons, FSCV reveals the extracellular dopamine concentrations available to activate target receptors. This distinction can be important, as recent studies suggest that dopamine transients can arise from influences, perhaps inputs onto dopaminergic axon terminals, other than NMDA receptor activation at the dopamine cell bodies (Sombers et al., 2009; Parker et al., 2010). Related to this, electrophysiology yields firing patterns of individual neurons but cannot confirm their neurochemical identity (e.g., dopaminergic versus GABAergic neuron). In contrast, dopamine fluctuations measured with FSCV are positively identified as dopamine. In addition, regional variation in dopamine release is more easily determined by measuring dopamine release than dopamine neuronal firing (Garris and Rebec, 2002), as there is heterogeneity in the projection targets of various cell groups within the midbrain and especially the VTA (Ikemoto, 2007). While the majority of reports of dopamine transient activity to date have focused on the NAc core and shell, spontaneous transients have also been characterized in dorsomedial striatum (Robinson et al., 2002) and olfactory tubercle (Robinson et al., 2002; Robinson and Wightman, 2004).

The first reports of dopamine transients were in the NAc in response to a novel environment (Rebec et al., 1997) and to the presentation of a sexually receptive rat (Robinson et al., 2001) both arguably important stimuli to a rat. Additional studies demonstrated that dopamine transients were not associated with any particular movement or behavior; instead, they were followed by approach and appetitive behaviors toward the stimulus rat (Robinson et al., 2002), consistent with theories of dopamine function in behavioral switching and reward-seeking. Some studies, including these initial reports, monitored dopamine release across time and at individual experimental events, such as a stimulus presentation or a drug injection. However, other studies have explored dopamine release during multiple-trial sessions, such as Pavlovian conditioning (e.g., Day et al., 2007) and operant self-administration of a reinforcer (e.g., Phillips et al., 2003; Roitman et al., 2004). These multi-trial 
paradigms allow more sensitive dopamine measurements due to signal-averaging to enhance the signal-to-noise of dopamine release that is consistently expressed at a repeated event such as an operant response or cue presentation. As more and more studies employ FSCV to monitor dopamine transients, some common findings have emerged.

(1) Dopamine transients occur across the striatum at a basal rate that varies across recording sites and can be pharmacologically manipulated. Just as individual dopamine neurons burst at a basal frequency (Freeman and Bunney, 1987; Overton and Clark, 1997; Hyland et al., 2002), dopamine transients are expressed at a basal rate in target areas. Generally, transients are more frequent in ventral striatum than dorsal striatum (Robinson et al., 2002), and few basal differences have been detected among the NAc core, shell, and olfactory tubercle (Robinson and Wightman, 2004; Aragona et al., 2008; Robinson et al., 2009). However, within a target nucleus, one may observe dramatic variability in transient expression from one recording site to another as the $100-\mu \mathrm{m}$ carbon-fiber microelectrode is lowered through the tissue (Wightman et al., 2007). This heterogeneity has resulted in the observation of "hot" and "cold" sites of dopamine transients that is independent of dopamine innervation, as dopamine release can be evoked with electrical stimulation even in the "cold" sites that do not readily support spontaneous dopamine transients (Robinson and Wightman, 2007; Wightman et al., 2007; Robinson et al., 2009). Moreover, these basal rates of dopamine transients can be increased by administration of dopamine transporter blockers, autoreceptor antagonists, and addictive drugs (Robinson and Wightman, 2004; Stuber et al., 2005; Cheer et al., 2007; Aragona et al., 2008). Thus, basal frequencies of dopamine transients are thought to reflect both the burst-firing characteristics of the dopaminergic neurons that innervate the recording site as well as the complement of transporter and receptors on those neurons. As dopaminergic tone is lower in the postpartum period (Afonso et al., 2009), understanding changes in basal rates of transients could be very informative.

(2) Dopamine transients are often coincident with the presentation of unexpected, salient stimuli. Just as burst-firing of dopamine neurons in awake animals were initially recorded during unexpected sensory stimulation such as experimenter approach, whisker stimulation, and novelty (for review, see Overton and Clark, 1997), dopamine transients have been reported to occur at the presentation of experimenter approach, novelty, sounds, and unfamiliar rats (for review, see Robinson and Wightman, 2007). Indeed, the unexpected nature of a stimulus appears to be an important factor in whether it evokes dopaminergic burst-firing (Mirenowicz and Schultz, 1994) and dopamine transients, as repeated presentation of a novel stimulus reduced the phasic dopaminergic response to that stimulus (Ljungberg et al., 1992; Rebec et al., 1997; Robinson et al., 2002). Thus, phasic dopamine signals to unexpected events may facilitate behavioral responses and learning about potentially important environmental stimuli (Redgrave et al., 1999, 2008; Alcaro et al., 2007; Schultz, 2007), and thus could play very important roles in the response to newly born pups and the various stimuli (olfactory, auditory, sensory) they create. Additionally, dopamine transients may contribute to the recognition of the subtly altered pup-produced stimuli as they change over pup development.

(3) Dopamine transients reflect learned cue-reward associations. The expression of both burst-firing of dopamine neurons and dopamine transients has been explicitly tied to reward and learning. Not only do unexpected rewards reliably induce phasic dopamine release, but cues that predict reward can do the same. In fact, phasic dopamine is hypothesized to act as an error predictor of reward (Schultz, 1998): when a reward is better than expected, phasic dopamine is increased, and when it is worse than expected, it is decreased. In this way, unexpected presentations of reward or reward-predictive cues are "better than expected" and trigger dopamine release. Furthermore, the phasic dopamine signal emerges over time as the relationship between the conditioned cue and the reward is learned (Schultz, 1998; Day et al., 2007; Owesson-White et al., 2008). Dopamine transients associated with cue-reward associations have been demonstrated both in Pavlovian and operant settings, with dopamine release time-locked to the presentation of cues predicting cocaine, sucrose, food, and intracranial stimulation. Figure 1 shows examples of dopamine release to the cue and a reward in the NAc of a rat after several days of Pavlovian conditioning. As previously reported (Day et al., 2007; Stuber et al., 2008), dopamine release is more robust to the cue than to the reward delivery after Pavlovian conditioning. Recently, optogenetics has been combined with FSCV to experimentally induce firing in dopaminergic neurons expressing the light-activated cation channel channelrhodopsin-2 (Tsai et al., 2009; Vickrey et al., 2009; Bass et al., 2010; Tecuapetla et al., 2010). Using light to stimulate these neurons, Tsai et al. (2009) demonstrated that phasic dopamine was sufficient to induce a conditioned place preference, providing an elegant confirmation that phasic dopamine release (and potentially glutamate corelease) regulates cue-reward learning. In the context of maternal behavior, this technique holds promise to also determine how phasic dopamine might regulate learning of pup stimuli.

(4) Dopamine transients appear to facilitate reward-seeking behavior. It has long been known that electrical stimulation of the mesolimbic dopamine pathway is reinforcing and can induce context-dependent motivated behavior (Valenstein et al., 1968), such as approaching and gnawing on a woodchip when it is available, or approaching a bottle and drinking when water is available. Indeed, a unifying theory of dopamine function is that it serves as a seeking system in the brain that is vital to the recognition of and approach toward rewarding stimuli that are necessary to survival, such as food, sex, and safety (Ikemoto and Panksepp, 1999; Alcaro et al., 2007). Thus, it is not surprising that dopamine transients have also been associated with appetitive and approach behaviors. In the first report of dopamine transients during operant selfadministration of a reward, electrical stimulation of dopamine was followed by approach to the lever (Phillips et al., 
2003). However, electrical stimulation of dopamine fibers inevitably includes stimulation of other neurons as well, so the effects are non-specific. Thus, an important finding was that spontaneous transients were observed at the initiation of approach to a lever in rats trained to self-administer sucrose (Roitman et al., 2004). In the future, we expect that more selective techniques such as optogenetic control of dopamine release can be used to confirm whether transients are necessary and sufficient to elicit approach behavior to obtain a reward.

\section{DOPAMINE TRANSIENTS DURING SOCIAL BEHAVIOR}

While several studies have now reported dopamine transients at the presentation of unexpected stimuli, social stimuli appear to be particularly effective. For example, in one recent study the frequency of dopamine transients in adult male rats increased 2 -fold from basal rates at the most effective non-social stimulus (a combination of a novel odor and experimenter approach), while

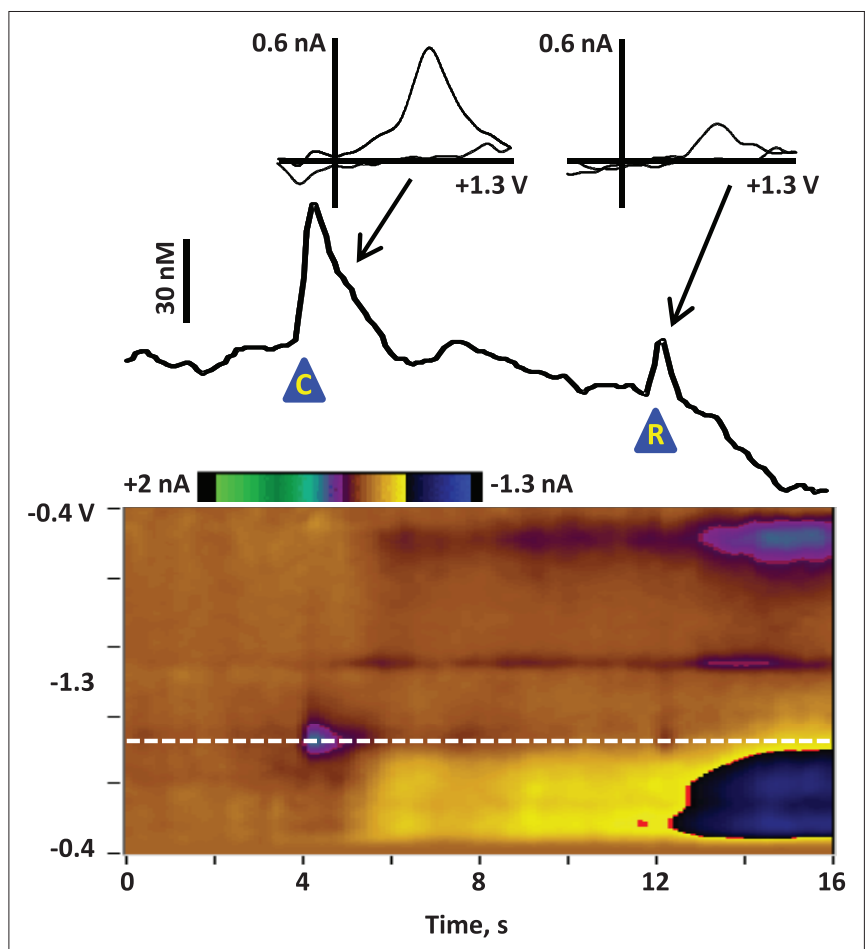

FIGURE 1 |Average dopamine release in the NAc core of a rat the presentation of a cue and reward after Pavlovian conditioning. The rat was trained for 7 days on a Pavlovian conditioning paradigm: each day it received 25 pairings of a cue (8-s lever extension and cue light illumination) and a reward $\left(0.1 \mathrm{ml}\right.$ of Ensure ${ }^{\circledR}$ chocolate drink). On the eighth day, dopamine was recorded in the NAc core during an identical Pavlovian session. The figure illustrates the dopamine release associated with cue and reward presentation, signal-averaged across the 25 trials. The color plot shows the changes in current at each applied potential over a 16-s window; cue presentation (" $\mathrm{C}$ ") is at $4 \mathrm{~s}$ and reward delivery (" $\mathrm{R}$ ") is at $12 \mathrm{~s}$. Current at the oxidation potential of dopamine (white dotted line) is depicted in the line trace above the color plot. The transients are confirmed to be dopaminergic by evaluation of the cyclic voltammograms (inset above). As previously reported (Day et al., 2007; Stuber et al., 2008), dopamine release is more robust to the cue than to the reward delivery after Pavlovian conditioning. it increased 3.6-fold at the presentation and brief interaction with another male rat (Robinson et al., 2011). Figure 2 shows examples of dopamine transients in the NAc of a male rat during interaction with another male. Dopamine release is evident at initial whisker contact and sniffing (left), as well as during anogenital sniffing (right). There are several interesting aspects of phasic dopamine release in this paradigm. First, the dopamine transients often occur at initial contact with the partner rat and are followed by appetitive behaviors such as orientation, approach, and sniffing (Robinson et al., 2002). Second, the number and amplitude of the dopamine transients to social stimuli appear to reflect motivation toward the partner rat. When dopamine release in adult male rats was monitored during brief interaction with sexually receptive females, non-receptive females or males, dopamine transients were most frequent with sexually receptive females and least frequent with males (Robinson et al., 2002). Third, the phasic dopamine response appears to habituate with repeated presentation of the same partner rat; that is, fewer dopamine transients are observed at a second presentation of a particular rat, despite the observation that behavior directed at the partner rat is not diminished (Robinson et al., 2002, 2011).

These findings suggest that the phasic dopamine release helps to shift the rat's behavior toward an unexpected partner rat, especially when the partner rat is motivationally significant, consistent with the role of phasic dopamine in behavioral switching (Redgrave et al., 1999), reward-seeking (Alcaro et al., 2007) and reward prediction (Schultz, 1998). Theories of dopamine function would suggest that dopamine transients at the presentation of social stimuli and initial interaction would reflect both the salience of the social stimulus and the unexpected nature. For example, while a sexually receptive female may be effective to trigger transients in a male rat when she unexpectedly appears, she does not necessarily continue to evoke transients when his behavior is already directed toward her. This may explain the habituation of dopamine transients to repeated presentations of stimulus rats, although recognition of the partner rat (lack of novelty) or simply an expectation that the rat will reappear (lack of surprise) may contribute as well. Interestingly, we recently monitored dopamine transients in socially deprived adolescent rats and found that dopamine transients during brief social interaction in adolescent rats did not habituate to a repeat presentation as occurs in socially deprived adults (Robinson et al., 2011). As previous studies have shown that social interaction is particularly rewarding in adolescent rats (Douglas et al., 2004), it is possible that the persistence of dopamine transients also reflects increased reward.

Our studies support the hypothesis that dopamine transients reflect appetitive aspects of social behavior rather than consummatory aspects. This was most clearly shown when, after measuring dopamine release to several brief interaction episodes, the male rat was allowed to copulate with the receptive female (Robinson et al., 2002). Fewer dopamine transients were observed during copulation as opposed to brief interactions, but most of these transients were followed within $5 \mathrm{~s}$ by sexual behaviors such as mounting, intromission, and ejaculation. Thus, even within copulatory episodes, the timing of transients is consistent with appetitive rather than consummatory aspects of sexual behavior. 


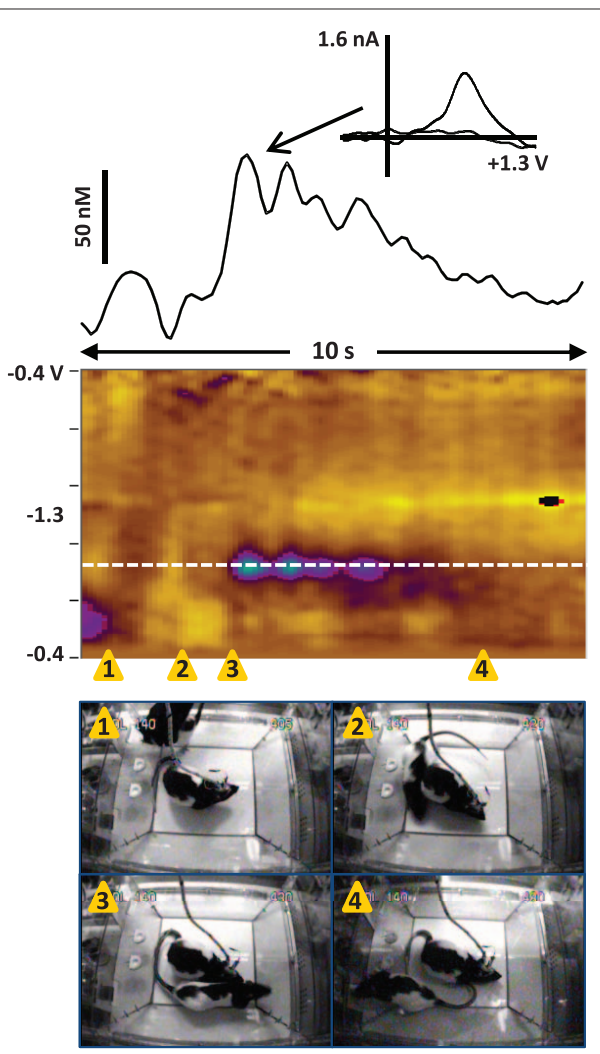

FIGURE 2 | Dopamine transients in the NAc core of male rats during brief interaction with another male. Left: Dopamine release is associated with initial whisker contact and sniffing of the peer. Right: Dopamine transients in a different rat occur during anogenital sniffing. The color plot shows the changes in current at each applied potential over a 10-s window, and current at the oxidation potential of dopamine (white dotted line) is depicted in the line trace above the color plot. The transients are confirmed to be dopaminergic by evaluation of the cyclic voltammograms (inset above). Snapshots from the video record of the
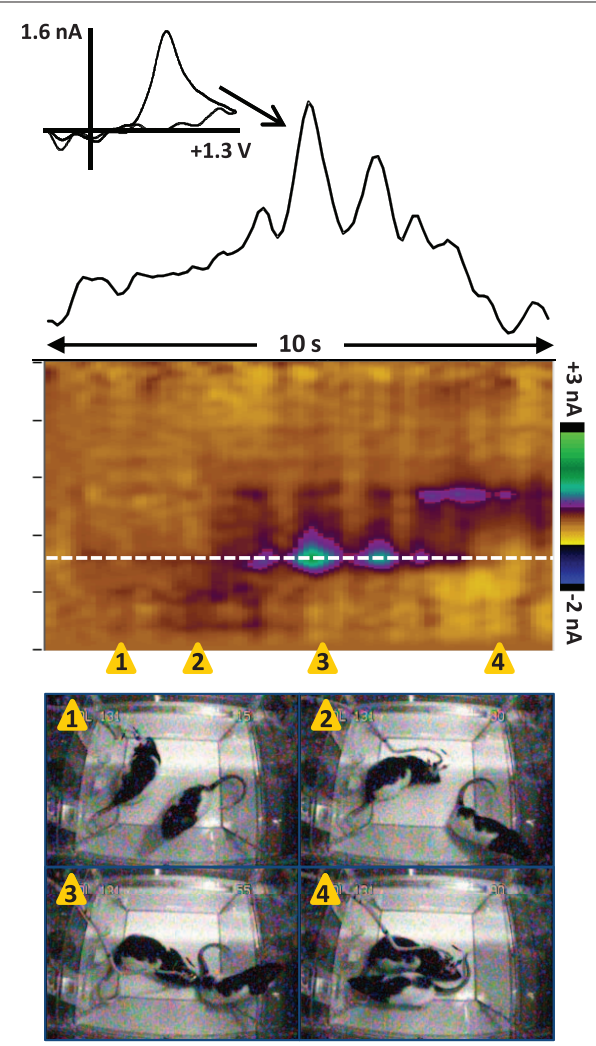

interactions are shown below the color plot and illustrate the behavioral events that co-occur with dopamine release; the timing of each snapshot is indicated by the orange triangles. Note that the test rats had been in the recording chamber for over 30 min prior to presentation of the peer rats. Left: 1, the peer rat is placed in the test chamber; 2 , The peer rat begins to walk around the test rat; 3 , the test rat sniffs the peer rat; 4 , the peer rat moves away from the test rat. Right: 1 , the test rat is facing away from the peer rat; 2 , the test rat orients toward the peer rat; 3 , the test rat sniffs the peer rat; 4 , the peer rat moves away from the test rat.

\section{DOPAMINE TRANSIENTS DURING MATERNAL BEHAVIOR}

In light of this research, it seems reasonable to speculate that dopamine transients are also important neural signals in maternal behavior, another stimulus-driven, motivated behavior. Maternal behavior represents a critical survival behavior, and one that is induced by both the unique postpartum hormonal state and by the sensory stimuli of the pups. Interestingly, male rats or virgin females actively avoid pups, but the incentive value of pups to postpartum dams overcomes any tendency to avoid or reject them; instead, a postpartum dam will approach and exhibit maternal behaviors toward pups immediately after delivery, even pups from another dam (Rosenblatt, 1994). These maternal-specific behaviors include nest building, pup retrieval, pup grooming (body and anogenital licking), and crouching to nurse the pups. Furthermore, these activities can be divided into appetitive (goal-directed behaviors, such as pup retrieval) and consummatory (behaviors once the goal has been obtained, such as nursing). Bouts of licking and grooming, another pup-directed behavior, may have both appetitive (approaching and handling the pup) and consummatory (licking and grooming sequences) aspects. The medial preoptic area (MPOA) of the hypothalamus coordinates all of these events, as its various projections can suppress avoidance and rejection of the pups, activate approach and appetitive behaviors toward the pups, and modulate consummatory aspects such as nursing posture (for review, see Numan and Woodside, 2010; Stolzenberg and Numan, 2011).

Thus, the MPOA and other hypothalamic nuclei, primed by the hormonal milieu of parturition, enhance the incentive salience of pups to a parturient dam to trigger appetitive, approach behavior. Mechanisms by which this influence can occur are the direct projections from the MPOA and from the adjacent ventral bed nucleus of the stria terminalis to the VTA (Numan and Smith, 1984; Numan and Numan, 1997), where they presumably affect dopamine neurons; the input from the MPOA includes oxytocin-expressing neurons (Shahrokh et al., 2010). Oxytocin is a neuropeptide that plays an important role in modulating appetitive aspects of maternal behavior (Pedersen and Boccia, 2002; Numan and Stolzenberg, 2009; Numan and Woodside, 2010). Notably, oxytocin likely arising from the parvocellular neurons of the paraventricular nucleus is released into both the MPOA and the VTA, where it modulates maternal behavior (Pedersen et al., 1994). Moreover, microinfusion of oxytocin into the VTA can trigger dopamine release into the NAc (Melis et al., 2007). 
When tonic dopamine concentrations in the NAc are compared between early postpartum dams and cycling virgin females, levels are lower in the dams at baseline (Afonso et al., 2009) despite having similar tissue concentrations of dopamine (Olazabal et al., 2004). However, extracellular dopamine concentrations rise in dams when pups are returned after a brief separation, and they rise even higher during vigorous maternal behaviors such as grooming dirt off of pups (Hansen et al., 1993; Lavi-Avnon et al., 2008). This tonic dopamine response to pup presentation is dependent on parturient hormones early postpartum (Afonso et al., 2009), but it is also experience-dependent, as tonic dopamine release can be induced by foster pups in dams that previously had litters (Afonso et al., 2008). The magnitude of dopamine release appears to vary with individual differences in maternal behavior: when dams were separated into high-licking and low-licking groups based on their pup-directed licking and grooming behavior, the high-licking dams exhibited larger dopamine-like signals in the NAc during a pup-directed licking and grooming bout than low-licking dams (Champagne et al., 2004). Interestingly, mere presentation of pup cues in the absence of maternal behavior can also induce tonic dopamine increases in postpartum dams but not in virgin rats (Afonso et al., 2009). Supporting these findings, EEG recordings in the VTA show distinct electrophysiological profiles in lactating dams versus cycling females in response to pup odors (Hernandez-Gonzalez et al., 2005). Together, these studies clearly indicate that tonic mesolimbic dopamine release increases during maternal interaction with pups and pup-associated cues, but the role of phasic dopamine transients has not been determined.

Based on observations of dopamine transients in other behaviors, we can make specific predictions regarding the potential role of dopamine transients in maternal behavior and when dopamine transients might occur. Consistent with its role to signal unexpected reward, dopamine transients would be expected to occur at pup presentation in parturient dams more frequently than in virgin female or male rats; this prediction is consistent with the ability of pups to act as reward (Wansaw et al., 2008) and reinforcers (Lee et al., 2000) in dams. While dopamine transients may also occur in virgin female or male rats in response to the novel and perhaps aversive salience of pups (Fleming and Luebke, 1981), we expect that this dopaminergic response would be less consistent or persistent than the response in postpartum dams, reflecting the different motivational value the pups hold for the various adult rats. Similarly, pup-predictive cues, such as ultrasonic pup vocalizations, would also be expected to trigger dopamine transients in dams. These transients would likely be followed by approach and retrieval, similar to the approach and appetitive behaviors we observed following dopamine transients in male sexual behavior (Robinson et al., 2002) and the approach to the lever observed rats trained to self-administer cocaine and sucrose (Phillips et al., 2003; Roitman et al., 2004). Thus, the function of dopamine transients in these instances would be to facilitate initiation and maintenance of seeking and appetitive aspects of maternal behavior. It would follow that disruption of this signal would block appetitive maternal behaviors. While local infusion of GABA agonists into the VTA (Numan et al., 2009) and dopamine D1 receptor antagonists in the NAc (Keer and Stern, 1999; Numan et al., 2005) block pup retrieval, these manipulations are not specific for phasic dopamine responses. A more explicit test of phasic dopamine would be to use optogenetics to selectively excite or inhibit dopaminergic inputs to the NAc at discrete times and observe the effect on appetitive behaviors such as pup retrieval.

What is less straightforward is whether dopamine transients might occur during consummatory aspects of maternal behavior, such as nursing and pup-directed licking and grooming. While these behaviors can be considered consummatory - behaviors that emerge once the desired object has been obtained - they also involve sensory stimuli to maintain the behavior, and those stimuli may trigger dopamine transients when they are salient. Of particular importance may be the pulsatile release of oxytocin during nursing bouts (Armstrong and Hatton, 2006), which can increase tonic DA release in the NAc (Melis et al., 2007). In addition, a bout of licking and grooming involves approaching, selecting, and picking up the pup - these may be mini-episodes of appetitive behaviors, in contrast to the more consummatory behavior of licking once the pup is obtained. Due to its time resolution, FSCV is an ideal method to investigate these different aspects of a licking and grooming bout as individual dopamine transients can be time-locked to specific events in the sequence.

We have recently recorded dopamine transients in the NAc core of a dam at postpartum day 4 to demonstrate the feasibility of recording during maternal behaviors and to begin to test our hypotheses of when dopamine transients will occur. While the data are preliminary, they suggest that dopamine transients do occur during maternal behavior, especially at pup cues and appetitive behaviors. Pups were removed from the dam and placed in a holding cage for $30 \mathrm{~min}$. Next, we monitored dopamine transients during the process of pup return and found that transients occur in a manner that is consistent with phasic dopamine triggered by unexpected, salient stimuli. Dopamine transients were detected and analyzed as previously described (Robinson et al., 2011). Movie S1 in Supplementary Material and Figure 3 show the neurochemical recording during a 15 -s period while the external chamber door is open and the investigator is gathering pups from the holding cage to return to the dam. During this time, the dam is oriented toward the investigator and the pups and actively sniffing and whisking. It is unknown whether sensory stimuli are associated with the exact timing of the transients, but we predict that pupassociated stimuli such as vocalizations and odors could trigger transients. Consistent with this idea, the largest dopamine transient occurred as the investigator began to gather pups (Figure 3, snapshot 2), which may have induced pup vocalizations heard by the dam. Such a finding would be consistent with measurements of tonic dopamine levels (Afonso et al., 2009) and reports of phasic dopamine signals to reward-predictive cues (Schultz, 1998; Robinson et al., 2008).

Next, we recorded dopamine immediately following pup return as the dam initiated pup retrieval, as shown in Movie S2 in Supplementary Material and Figure 4. In the seconds following pup return, the dam initially scanned and sniffed several pups as well as the test chamber. However, a large dopamine transient occurred while the rat was facing away from the pups and apparently sniffing the test cage (snapshots 5 and 6). As with the dopamine transients observed in Figure 3, is it possible that ultrasonic pup vocalizations triggered the dopamine release, as pup vocalizations can act as auditory cues 


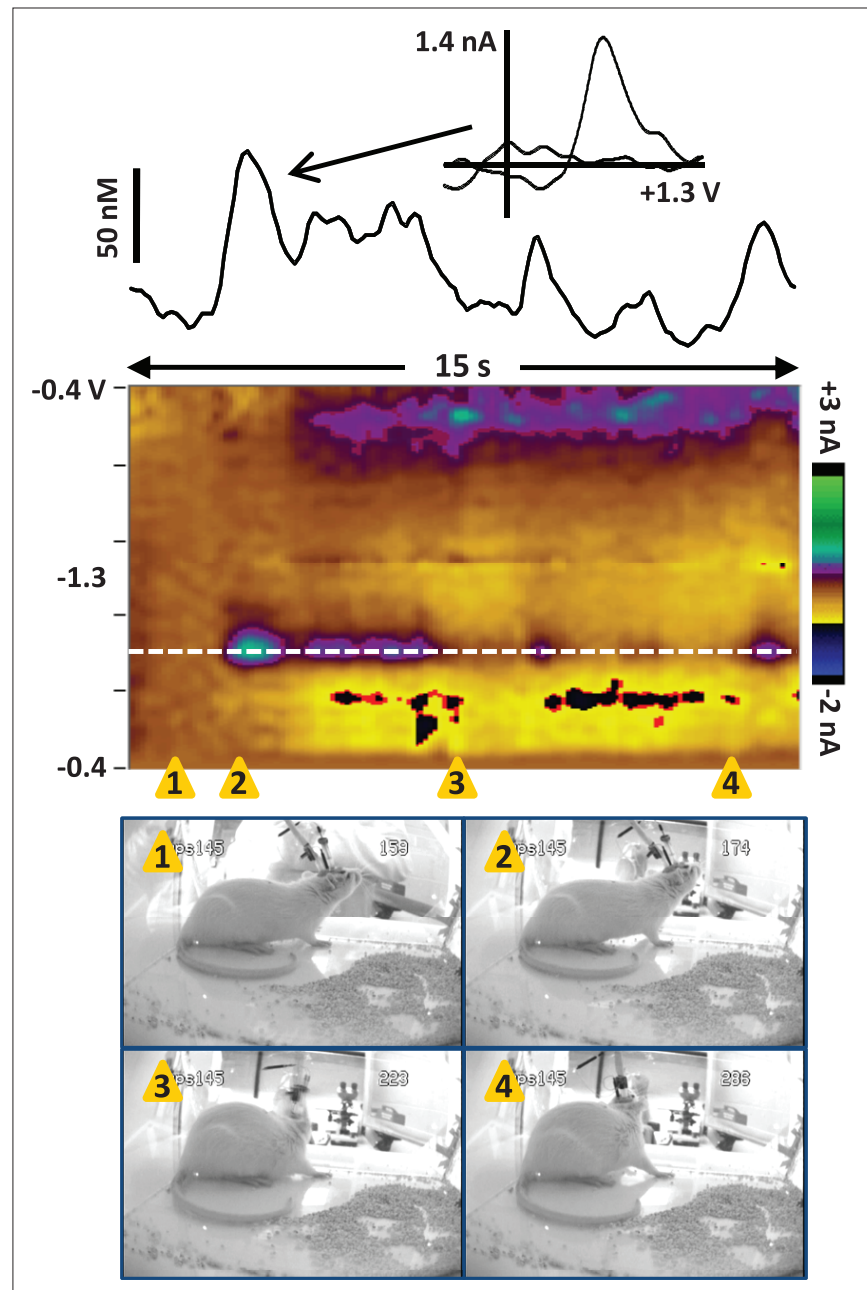

FIGURE 3 | Dopamine transients in the NAc core of a dam in the seconds before pup return (data also shown in Movie S1 in Supplementary Material). The color plot shows the changes in current at each applied potential over a 15-s window, and current at the oxidation potential of dopamine (white dotted line) is depicted in the line trace above the color plot. The timing of the snapshots is indicated by the orange triangles. In this sequence, the investigator has opened the door of the test chamber (snapshot 1) and is gathering pups to return to the dam (snapshots 2-4). The dam is positioned by the plexiglass front of the chamber, actively sniffing/ whisking and leaning in the direction of the investigator and the pups. Several dopamine transients occur while the dam is oriented toward the investigator and the pups. The transients are confirmed to be dopaminergic by evaluation of the cyclic voltammograms (inset above).

to direct maternal behavior (Brunelli et al., 1994; Zimmerberg et al., 2003). Alternatively, the dam may have been scanning the chamber to see where pups were scattered before initiating retrieval. Notably, immediately after the peak of that transient, the rat turned toward the pups (snapshot 7) and began to touch and sniff them (snapshot 8 ), inducing further dopamine release. Finally a smaller dopamine transient occurred as the dam retrieved the first pup (snapshots 12 and 13). The following is a detailed description of the dam's behavior at each snapshot in the sequence of Figure 4, and those events concurrent with confirmed dopamine release (meeting criteria described in Robinson et al., 2011) are depicted in bold type:
1) $0.5 \mathrm{~s}-$ touch/sniff pup while experimenter closes cage door

2) $1.3 \mathrm{~s}$ - turn toward door and investigator's hand, sniff

3) $3.4 \mathrm{~s}-$ touch/sniff pup

4) $5 \mathrm{~s}$ - touch/sniff different pup

5) $6 \mathrm{~s}$ - turn away from pups, sniffing cage

6) $7 s$ - sniffing cage

7) $7.8 s$ - turn back toward pups

8) $8.3 \mathrm{~s}-$ touch/sniff pup

9) $9 \mathrm{~s}-$ touch/sniff pup

10) $9.5 \mathrm{~s}-$ touch/sniff different pup

11) $10 \mathrm{~s}-$ touch/sniff different pup

12) $10.4 s$ - grasp pup with mouth

13) $10.8 \mathrm{~s}$ - pull pup back toward nest

14) $11.4 \mathrm{~s}-$ touch/sniff pup

15) $11.8 \mathrm{~s}$ - move forward, touch/sniff pup

16) $12.6 \mathrm{~s}-$ touch/sniff different pup

17) $12.9 \mathrm{~s}$ - grasp pup with mouth

18) $13.8 \mathrm{~s}$ - pull pup back to nest

Thus, these preliminary data indicate that dopamine transients can occur as predicted during maternal behavior: at salient stimuli, during pup investigation, and immediately before and during pup retrieval. Future studies will need to delineate the contribution of pup-associated cues such as vocalizations by concurrently monitoring ultrasonic frequencies. In addition, the potential role of phasic dopamine during lactation should be explored, as the connection between oxytocin and dopamine transmission is evident but not fully understood. It is interesting to note that the second act of pup retrieval was neither preceded nor followed by a large dopamine transient, suggesting that transients may be especially important for the initiation of such behavior, but that once the behavior is initiated it continues via other mechanisms. This interpretation is consistent with dopamine transients' role in behavioral switching. Further investigation is clearly needed to understand this phenomenon more clearly.

There are experimental considerations that may guide future studies of phasic dopamine release during maternal behavior. One important focus of research would be to monitor dopamine release during ongoing maternal behavior in as naturalistic a situation as possible, such as shown in Figure 4. The advantage of this type of "free behavior" measurement is that we can determine when dopamine transients occur and associate them with stimuli and behaviors that precede or follow them. This is the approach we have successfully used for dopamine release during brief social interaction and male sexual behavior (Robinson et al., 2001, 2002, 2011), and differences in the frequency of dopamine transients during multiple behavioral epochs can be detected (e.g., solitude versus social interaction; interaction with a male versus a receptive female). Using this approach, we expect that dopamine transients would be higher during epochs of appetitive maternal behaviors as compared to solitude or lactation, and that the frequency of dopamine transients would be proportional to the amount of maternal behavior exhibited, similar to the tonic measurements previously described (Hansen et al., 1993; Champagne et al., 2004; Lavi-Avnon et al., 2008). In addition to a video record of the test session that is time-stamped to 


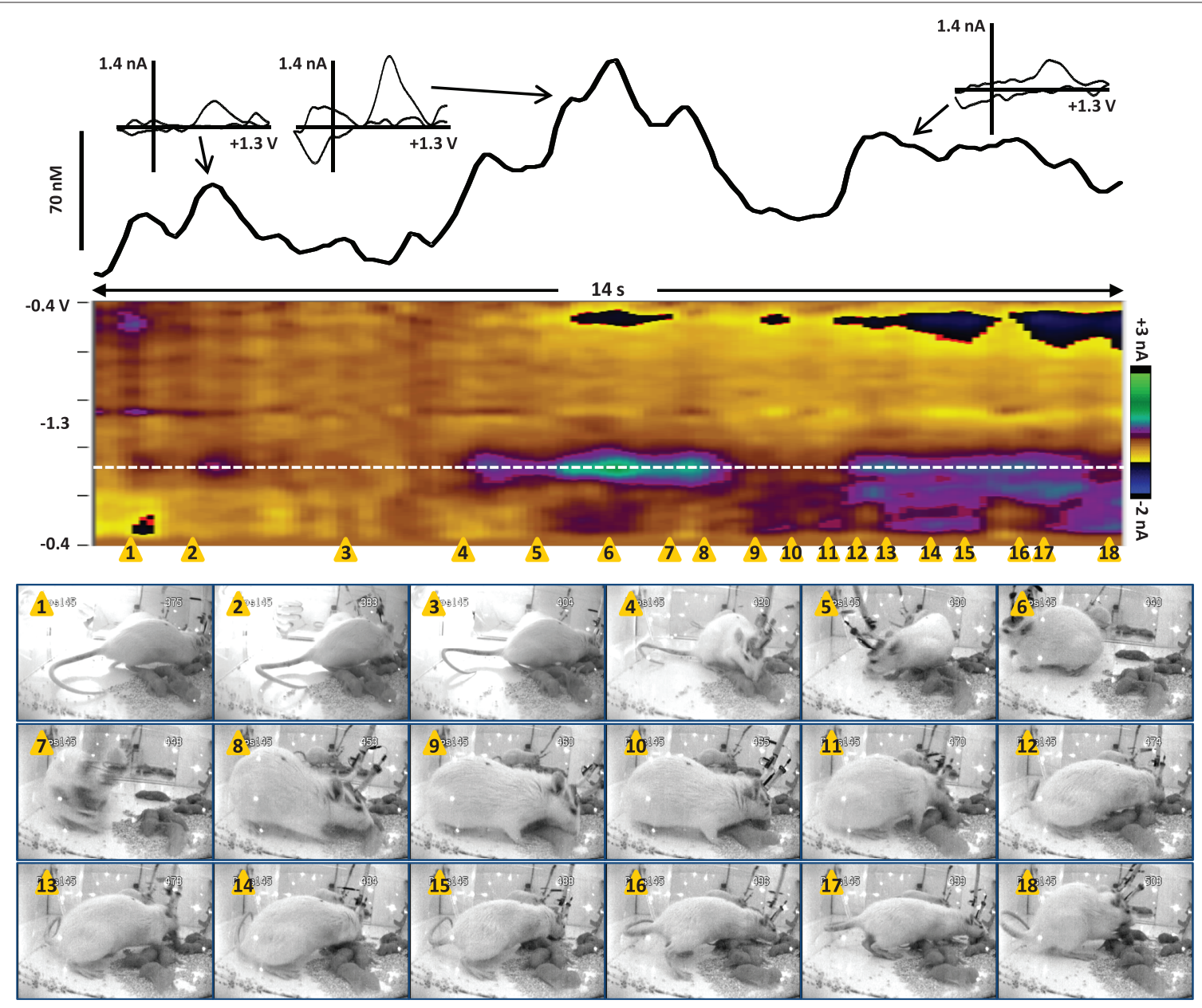

FIGURE 4 | Dopamine transients in the NAc core of a dam at the onset of retrieval after pups are returned (data also shown in Movie S2 in Supplementary Material). The color plot shows the changes in current at each applied potential over a 14-s window, and current at the oxidation potential of dopamine (white dotted line) is depicted in the line trace above the color plot. The timing of the snapshots is indicated by the orange triangles. This sequence begins $4 \mathrm{~s}$ after the pups were returned; for full description of the dam's behavior, see the text. Dopamine transients are associated with closing the test chamber door, investigating the pups and test chamber, and pup retrieval. The largest dopamine release at 6.3-8.3 s (near snapshots 5-8) preceded a series of pup retrievals that started at $10.4 \mathrm{~s}$ (snapshot 12) and continued for two more minutes until the dam crouched for nursing. The transients are confirmed to be dopaminergic by evaluation of the cyclic voltammograms (inset above). the neurochemical measurement, the ideal experiment will include a time-stamped recording of ultrasonic vocalizations, as these may be important auditory cues to the dam (Brunelli et al., 1994; Zimmerberg et al., 2003).

However, a major limitation to dopamine measurement during free behavior is the fact that it yields correlational rather than causal relationships. Thus, follow-up studies can employ experimental paradigms that allow more precise determination of antecedents of dopamine release as well as comparison among experimental groups. For example, various pup cues (odors, vocalizations, movements) can be separately presented to dams or to virgin rats to compare their relative efficacy to trigger dopamine release. This design can include time-locked and repeated cue presentations, which has the advantage of allowing signal-averaging of the dopamine signal. Moreover, non-pup cues can be presented as positive controls. Similarly, retrieval of pups can be constrained such that only one pup is retrieved at a time from a particular spot, such that more consistent approach, lifting, and delivery of pup retrieval can be elicited and associated with dopamine release. Interestingly, dams can be trained to perform an operant behavior for access to pups (Lee et al., 2000), allowing measurements of pupseeking behavior and the associated dopamine release, similar to self-administration of drugs and consumed reward (e.g., Phillips et al., 2003; Roitman et al., 2004). Another level of investigation would be to examine the effectiveness of various pup cues to elicit dopamine release and maternal behavior in dams. For example, ultrasonic vocalizations of pups are more effective to elicit maternal response when pup odors are also present (Rohitsingh et al., 2011), and preliminary data suggest that the quality (e.g., frequency, harmonics, rate) of pup vocalizations can be influenced by genetic manipulation (Scattoni et al., 2009) or prenatal events such as cocaine exposure (preliminary data: Cox et al., 2010) and may, thus, contribute to changes in maternal behavioral and neurochemical responses. 


\section{SUMMARY AND FUTURE DIRECTIONS}

Phasic dopamine release has a special function in motivated behaviors that is still being elucidated, but appears to be focused on predictive and appetitive aspects of reward-seeking. Dopamine transients are qualitatively different than tonic dopamine levels, both due to the time frames in which they occur, their potential receptor targets, and corelease of glutamate. When examined during social behavior and reward conditioning, transients tend to occur during unexpected salient stimuli and appetitive and approach behaviors. Therefore, we expect that they also play an important role in maternal behavior: particularly in the expression of incentive value of pup cues that lead to retrieval and appetitive aspects of licking and grooming. Systematic studies during maternal behavior are needed to first describe the occurrence of dopamine transients at various events, then to manipulate the expression of transients and observe effects on behavior, or vice versa. For example, predictions can be made based on the hormonal state of the female: pup-associated cues would be expected to trigger more dopamine transients in dams early versus late postpartum, and more in maternally experienced rats than in virgins. Furthermore, blocking dopamine transients pharmacologically or with optogenetic manipulation would be predicted to substantially reduce or delay appetitive maternal behaviors. Finally, dopamine transients in regions beyond the NAc can be investigated to explore their potential role in pup-directed action selection or the development of habitual responses driven by pup-associated cues.

Once the role of dopamine transients in normal maternal behavior is better understood, that knowledge can be used as the foundation to study animal models of disrupted maternal behavior, such as inattention and neglect due to stress or drug exposure. For example, chronic and acute cocaine exposures cause deficits in retrieval, crouching, and licking behaviors in postpartum rats (Johns et al., 1994, 1998, 2005). These drug treatments also decrease oxytocin in the VTA (Johns et al., 1997), which could affect VTA neuronal firing and, thus, dopamine release (Melis et al., 2007). As exposure to drugs of abuse can alter dopamine neuronal plasticity (Stuber et al., 2010b) and phasic release (Stuber et al., 2005), it is possible that the neuroadaptations induced by pregnancy and lactation are prevented or delayed in the drug-exposed dam. Similarly, maternal behaviors can be disrupted by exposure to stressful environments during pregnancy or lactation as well as by increased circulating stress hormones (Bosch et al., 2007; Brummelte and Galea, 2010). Stress response signaling systems, including corticotrophin releasing factor and corticosterone acting respectively through CRF1 and

\section{REFERENCES}

Afonso, V. M., Grella, S. L., Chatterjee, D., and Fleming, A. S. (2008). Previous maternal experience affects accumbal dopaminergic responses to pupstimuli. Brain Res. 1198, 115-123.

Afonso, V. M., King, S., Chatterjee, D., and Fleming, A. S. (2009). Hormones that increase maternal responsiveness affect accumbal dopaminergic responses to pup- and food-stimuli in the female rat. Horm. Behav. 56, 11-23.

Alcaro, A., Huber, R., and Panksepp, J. (2007). Behavioral functions of the mesolimbic dopaminergic system: an affective neuroethological perspective. Brain Res. Rev. 56, 283-321.

Aragona, B. J., Cleaveland, N. A., Stuber, G. D., Day, J. J., Carelli, R. M., and Wightman, R. M. (2008). Preferential enhancement of dopamine transmission within the nucleus accumbens shell by cocaine is attributable to a direct increase in phasic dopamine release events. J. Neurosci. 28, 8821-8831.

Armstrong, W. E., and Hatton, G. I. (2006). The puzzle of pulsatile

glucocorticoid receptors, can influence dopaminergic neuronal firing in the VTA, dopamine release in the NAc and synaptic plasticity in NAc neurons (Lodge and Grace, 2005; Campioni et al., 2009). Thus, it is possible that disruptions of phasic dopamine transmission could be one neurobiological mechanism underlying deficits in maternal behavior following drug use or stress, and that further study of this aspect of dopamine transmission may open avenues for intervention and restoration of maternal function.

\section{ACKNOWLEDGMENTS}

The authors gratefully acknowledge the lab of Dr. Josephine M. Johns for supply of rats for dopamine measurements in maternal behavior and technical support from Abigail Jamieson-Drake. We thank the NIH-National Institute of Alcoholism and Alcohol Abuse (NADIA Project 1-U01-AA019972 and 1-U24-AA020024, R01 AA018008, and 5-P60-AA011605-11-14), the NIH-National Institute of Drug Abuse (P01 DA022446 to JMJ), the Foundation of Hope and the Bowles Center for Alcohol Studies at the University of North Carolina for support. We also thank Dr. Tatiana Shnitko and Dr. Katherine Smith for critical reading of the manuscript. The content is solely the responsibility of the authors and does not necessarily represent the official views of the National Institute of Alcoholism and Alcohol Abuse, the National Institute on Drug Abuse, or the National Institutes of Health.

\section{SUPPLEMENTARY MATERIAL}

The Movies 1 and 2 for this article can be found online at http:// www.frontiersin.org/child_and_neurodevelopmental_psychiatry/ abstract/10294

MOVIE S1 | Dopamine transients in the NAc core of a dam in the seconds before pup return (data also shown in Figure 3). Behavior (top): The dam is positioned by the plexiglass front of the chamber, actively sniffing/whisking and leaning in the direction of the investigator and the pups. Dopamine trace (bottom): Several dopamine transients (shown in yellow) occur while the dam is oriented toward the investigator and the pups. Current at the oxidation potential of dopamine scrolls on screen in real-time with the video; the timing signal from the voltammetric instrumentation is time-stamped on the top right of the video recording.

MOVIE S2 | Dopamine transients in the NAc core of a dam at the onset of retrieval after pups are returned (data also shown in Figure 4). Behavior (top): As the chamber door is shut, the dam scans the nest area, then begins to retrieve pups. Dopamine trace (bottom): Dopamine transients are associated with closing the test chamber door, investigating the pups and test chamber, and pup retrieval. Current at the oxidation potential of dopamine scrolls on screen in real-time with the video; the timing signal from the voltammetric instrumentation is timestamped on the top right of the video recording.

oxytocin secretion during lactation: some new pieces. Am. J. Physiol. Regul. Integr. Comp. Physiol. 291, R26-R28.

Bass, C. E., Grinevich, V. P., Vance, Z. B., Sullivan, R. P., Bonin, K. D., and Budygin, E. A. (2010). Optogenetic control of striatal dopamine release in rats. J. Neurochem. 114, 1344-1352.

Berke, J. D., and Hyman, S. E. (2000). Addiction, dopamine, and the molecular mechanisms of memory. Neuron 25, 515-532.

Borland, L. M., Shi, G., Yang, H., and Michael, A. C. (2005). Voltammetric study of extracellular dopamine near microdialysis probes acutely implanted in the striatum of the anesthetized rat. J. Neurosci. Methods 146, 149-158.

Bosch, O. J., Musch, W., Bredewold, R., Slattery, D. A., and Neumann, I. D. (2007). Prenatal stress increases HPA axis activity and impairs maternal care in lactating female offspring: implications for postpartum mood disorder. Psychoneuroendocrinology32,267-278.

Brummelte, S., and Galea, L. A. (2010). Chronic corticosterone during 
pregnancy and postpartum affects maternal care, cell proliferation and depressive-like behavior in the dam. Horm. Behav. 58, 769-779.

Brunelli, S. A., Shair, H. N., and Hofer, M.A. (1994). Hypothermic vocalizations of rat pups (Rattus norvegicus) elicit and direct maternal search behavior. J. Comp. Psychol. 108, 298-303.

Campioni, M. R., Xu, M., and McGehee, D. S. (2009). Stress-induced changes in nucleus accumbens glutamate synaptic plasticity. J. Neurophysiol. 101, 3192-3198.

Champagne, F.A., Chretien, P., Stevenson, C. W., Zhang, T. Y., Gratton, A., and Meaney, M. J. (2004). Variations in nucleus accumbens dopamine associated with individual differences in maternal behavior in the rat. J. Neurosci. 24, 4113-4123.

Cheer, J. F., Wassum, K. M., Sombers, L.A., Heien, M. L., Ariansen, J. L., Aragona, B. J., Phillips, P. E., and Wightman, R. M. (2007). Phasic dopamine release evoked by abused substances requires cannabinoid receptor activation. J. Neurosci. 27, 791-795.

Cox, E., Jones, G., Williams, S., McMurray, M., Jamieson-Drake, A., Zeskind, P., Hodge, C., Grewen, K., and Johns, J. M. (2010). "Prenatal cocaine exposure alters human and rodent infant vocalizations: implications for maternal care and neural integrity," in Abstracts of the International Behavioral Neuroscience Society, Villasimius, Italy, 19, \#136.

Day, J. J., Roitman, M. F., Wightman, R. M., and Carelli, R. M. (2007). Associative learning mediates dynamic shifts in dopamine signaling in the nucleus accumbens. Nat. Neurosci. 10, 1020-1028.

de Wit, S., Barker, R. A., Dickinson, A. D., and Cools, R. (2011). Habitual versus goal-directed action control in Parkinson disease. J. Cogn. Neurosci. 23, 1218-1229.

Douglas, L. A., Varlinskaya, E. I., and Spear, L. P. (2004). Rewarding properties of social interactions in adolescent and adult male and female rats: impact of social versus isolate housing of subjects and partners. Dev. Psychobiol. 45, 153-162.

Fleming, A. S., and Luebke, C. (1981). Timidity prevents the virgin female rat from being a good mother: emotionality differences between nulliparous and parturient females. Physiol. Behav. 27, 863-868.

Floresco, S. B., West, A. R., Ash, B., Moore, H., and Grace, A. A. (2003). Afferent modulation of dopamine neuron firing differentially regulates tonic and phasic dopamine transmission. Nat. Neurosci. 6, 968-973.
Freeman, A. S., and Bunney, B. S. (1987). Activity of A9 and A10 dopaminergic neurons in unrestrained rats: further characterization and effects of apomorphine and cholecystokinin. Brain Res. 405, 46-55.

Garris, P. A., and Rebec, G. V. (2002). Modeling fast dopamine neurotransmission in the nucleus accumbens during behavior. Behav. Brain Res. 137, 47-63.

Hansen, S., Bergvall, A. H., and Nyiredi, S. (1993). Interaction with pups enhances dopamine release in the ventral striatum of maternal rats: a microdialysis study. Pharmacol. Biochem. Behav. 45, 673-676.

Hauber, W. (2010). Dopamine release in the prefrontal cortex and striatum: temporal and behavioural aspects. Pharmacopsychiatry 43(Suppl. 1), S32-S41.

Hernandez-Gonzalez, M., PrietoBeracoechea, C., Navarro-Meza, M., Ramos-Guevara, J.P., Reyes-Cortes, R., and Guevara, M. A. (2005). Prefrontal and tegmental electrical activity during olfactory stimulation in virgin and lactating rats. Physiol. Behav. 83, 749-758.

Hnasko, T. S., Chuhma, N., Zhang, H., Goh, G. Y., Sulzer, D., Palmiter, R. D., Rayport, S., and Edwards, R. H. (2010). Vesicular glutamate transport promotes dopamine storage and glutamate corelease in vivo. Neuron 65 , 643-656.

Hyland, B. I., Reynolds, J. N., Hay, J., Perk, C. G., and Miller, R. (2002). Firing modes of midbrain dopamine cells in the freely moving rat. Neuroscience 114, 475-492.

Ikemoto, S. (2007). Dopamine reward circuitry: two projection systems from the ventral midbrain to the nucleus accumbens-olfactory tubercle complex. Brain Res. Rev. 56, 27-78.

Ikemoto, S., and Panksepp, J. (1999). The role of nucleus accumbens dopamine in motivated behavior: a unifying interpretation with special reference to reward-seeking. Brain Res. Brain Res. Rev. 31, 6-41.

Johns, J. M., Elliott, D. L., Hofler, V. E., Joyner, P. W., McMurray, M. S., Jarrett, T. M., Haslup, A. M., Middleton, C. L., Elliott, J. C., and Walker, C. H. (2005). Cocaine treatment and prenatal environment interact to disrupt intergenerational maternal behavior in rats. Behav. Neurosci. 119, 1605-1618.

Johns, J. M., Lubin, D. A., Walker, C. H., Meter, K. E., and Mason, G. A. (1997). Chronic gestational cocaine treatment decreases oxytocin levels in the medial preoptic area, ventral tegmental area and hippocampus in Sprague-Dawley rats. Neuropeptides 31, 439-443.

Johns, J. M., Nelson, C. J., Meter, K. E., Lubin, D. A., Couch, C. D., Ayers,
A., and Walker, C. H. (1998). Dosedependent effects of multiple acute cocaine injections on maternal behavior and aggression in Sprague-Dawley rats. Dev. Neurosci. 20, 525-532.

Johns, J. M., Noonan, L. R., Zimmerman, L. I., Li, L., and Pedersen, C. A. (1994). Effects of chronic and acute cocaine treatment on the onset of maternal behavior and aggression in SpragueDawley rats. Behav. Neurosci. 108, 107-112.

Justice, J. B. Jr. (1993). Quantitative microdialysis of neurotransmitters. $J$. Neurosci. Methods 48, 263-276.

Kawagoe, K. T., Garris, P.A., Wiedemann, D. J., and Wightman, R. M. (1992). Regulation of transient dopamine concentration gradients in the microenvironment surrounding nerve terminals in the rat striatum. Neuroscience 51, 55-64.

Keer, S. E., and Stern, J. M. (1999) Dopamine receptor blockade in the nucleus accumbens inhibits maternal retrieval and licking, but enhances nursing behavior in lactating rats. Physiol. Behav. 67, 659-669.

Lapish, C.C., Seamans, J.K., and Chandler, L. J. (2006). Glutamate-dopamine cotransmission and reward processing in addiction. Alcohol. Clin. Exp. Res. 30, 1451-1465.

Lavi-Avnon, Y., Weller, A., Finberg, J. P., Gispan-Herman, I., Kinor, N., Stern, Y., Schroeder, M., Gelber, V., Bergman, S. Y., Overstreet, D. H., and Yadid, G. (2008). The reward system and maternal behavior in an animal model of depression: a microdialysis study. Psychopharmacology (Berl.) 196, 281-291.

Lee, A., Clancy, S., and Fleming, A. S. (2000). Mother rats bar-press for pups: effects of lesions of the mpoa and limbic sites on maternal behavior and operant responding for pupreinforcement. Behav. Brain Res. 108, 215-231.

Ljungberg, T., Apicella, P., and Schultz, W. (1992). Responses of monkey dopamine neurons during learning of behavioral reactions. J. Neurophysiol. 67, 145-163.

Lodge, D. J., and Grace, A. A. (2005). Acute and chronic corticotropin-releasing factor 1 receptor blockade inhibits cocaine-induced dopamine release: correlation with dopamine neuron activity. J. Pharmacol. Exp. Ther. 314, 201-206.

Logman, M.J., Budygin, E.A., Gainetdinov, R. R., and Wightman, R. M. (2000). Quantitation of in vivo measurements with carbon fiber microelectrodes. J. Neurosci. Methods 95, 95-102.

Lovinger, D. M. (2010). Neurotransmitter roles in synaptic modulation, plasticity and learning in the dorsal striatum. Neuropharmacology 58, 951-961.
Lu, Y., Peters, J. L., and Michael, A. C. (1998). Direct comparison of the response of voltammetry and microdialysis to electrically evoked release of striatal dopamine. J. Neurochem. 70, 584-593.

Melis, M. R., Melis, T., Cocco, C., Succu, S., Sanna, F., Pillolla, G., Boi, A., Ferri, G. L., and Argiolas, A. (2007). Oxytocin injected into the ventral tegmental area induces penile erection and increases extracellular dopamine in the nucleus accumbens and paraventricular nucleus of the hypothalamus of male rats. Eur. J. Neurosci. 26, 1026-1035.

Michael, D., Travis, E. R., and Wightman, R. M. (1998). Color images for fastscan CV measurements in biological systems. Anal. Chem. 70, 586A-592A.

Mirenowicz, J., and Schultz, W. (1994). Importance of unpredictability for reward responses in primate dopamine neurons. J. Neurophysiol. 72, 1024-1027.

Numan, M. (2007). Motivational systems and the neural circuitry of maternal behavior in the rat. Dev. Psychobiol. 49, 12-21.

Numan, M., and Numan, M. J. (1997). Projection sites of medial preoptic area and ventral bed nucleus of the stria terminalis neurons that express Fos during maternal behavior in female rats. J. Neuroendocrinol. 9, 369-384.

Numan, M., Numan, M. J., Pliakou, N., Stolzenberg, D. S., Mullins, O. J., Murphy, J. M., and Smith, C. D. (2005). The effects of D1 or D2 dopamine receptor antagonism in the medial preoptic area, ventral pallidum, or nucleus accumbens on the maternal retrieval response and other aspects of maternal behavior in rats. Behav. Neurosci. 119, 1588-1604.

Numan, M., and Smith, H. G. (1984). Maternal behavior in rats: evidence for the involvement of preoptic projections to the ventral tegmental area. Behav. Neurosci. 98, 712-727.

Numan, M., and Stolzenberg, D. S. (2009). Medial preoptic area interactions with dopamine neural systems in the control of the onset and maintenance of maternal behavior in rats. Front. Neuroendocrinol. 30:1. doi: 10.1016/j. yfrne.2008.10.002

Numan, M., Stolzenberg, D. S., Dellevigne, A. A., Correnti, C. M., and Numan, M. J. (2009). Temporary inactivation of ventral tegmental area neurons with either muscimol or baclofen reversibly disrupts maternal behavior in rats through different underlying mechanisms. Behav. Neurosci. 123, 740-751.

Numan, M., and Woodside, B. (2010). Maternity: neural mechanisms, motivational processes, and physiological 
adaptations. Behav. Neurosci. 124, 715-741.

Olazabal, D. E., Abercrombie, E., Rosenblatt, J. S., and Morrell, J. I. (2004). The content of dopamine, serotonin, and their metabolites in the neural circuit that mediates maternal behavior in juvenile and adult rats. Brain Res. Bull. 63, 259-268.

Overton, P. G., and Clark, D. (1997). Burst firing in midbrain dopaminergic neurons. Brain Res. Rev. 25, 312-334.

Owesson-White, C.A., Cheer, J. F., Beyene, M., Carelli, R. M., and Wightman, R. M. (2008). Dynamic changes in accumbens dopamine correlate with learning during intracranial self-stimulation. Proc. Natl. Acad. Sci. U.S.A. 105, 11957-11962.

Parker, J. G., Zweifel, L. S., Clark, J. J., Evans, S. B., Phillips, P.E., and Palmiter, R.D. (2010).Absence of NMDA receptors in dopamine neurons attenuates dopamine release but not conditioned approach during Pavlovian conditioning. Proc. Natl. Acad. Sci. U.S.A. 107, 13491-13496.

Pedersen, C. A., and Boccia, M. L. (2002). Oxytocin links mothering received, mothering bestowed and adult stress responses. Stress 5, 259-267.

Pedersen, C. A., Caldwell, J. D., Walker, C., Ayers, G., and Mason, G. A. (1994). Oxytocin activates the postpartum onset of rat maternal behavior in the ventral tegmental and medial preoptic areas. Behav. Neurosci. 108, 1163-1171.

Phillips, A. G., Vacca, G., and Ahn, S. (2008). A top-down perspective on dopamine, motivation and memory. Pharmacol. Biochem. Behav. 90, 236-249.

Phillips, P. E., Stuber, G. D., Heien, M. L., Wightman, R. M., and Carelli, R. M. (2003). Subsecond dopamine release promotes cocaine seeking. Nature 422, 614-618.

Rebec, G. V., Christensen, J. R., Guerra, C., and Bardo, M. T. (1997). Regional and temporal differences in realtime dopamine efflux in the nucleus accumbens during free-choice novelty. Brain Res. 776, 61-67.

Redgrave, P., Gurney, K., and Reynolds, J. (2008). What is reinforced by phasic dopamine signals? Brain Res. Rev. 58, 322-339.

Redgrave, P., Prescott, T. J., and Gurney, K. (1999). Is the short-latency dopamine response too short to signal reward error? Trends Neurosci. 22, 146-151.

Richfield, E. K., Penney, J. B., and Young, A. B. (1989). Anatomical and affinity state comparisons between dopamine D1 and $\mathrm{D} 2$ receptors in the rat central nervous system. Neuroscience 30, 767-777.

Robinson, D. L., Heien, M. L., and Wightman, R. M. (2002). Frequency of dopamine concentration transients increases in dorsal and ventral striatum of male rats during introduction of conspecifics. J. Neurosci. 22, 10477-10486.

Robinson, D. L., Hermans, A., Seipel, A. T., and Wightman, R. M. (2008). Monitoring rapid chemical communication in the brain. Chem. Rev. 108, 2554-2584.

Robinson, D. L., Howard, E. C. McConnell, S., Gonzales, R. A., and Wightman, R. M. (2009). Disparity between tonic and phasic ethanolinduced dopamine increases in the nucleus accumbens of rats. Alcohol. Clin. Exp. Res. 33, 1187-1196.

Robinson, D. L., Phillips, P. E., Budygin, E. A., Trafton, B. J., Garris, P. A., and Wightman, R. M. (2001). Sub-second changes in accumbal dopamine during sexual behavior in male rats. Neuroreport 12, 2549-2552.

Robinson, D. L., and Wightman, R. M. (2004). Nomifensine amplifies subsecond dopamine signals in the ventral striatum of freely-moving rats. $J$. Neurochem. 90, 894-903.

Robinson, D. L., and Wightman, R. M. (2007). "Rapid dopamine release in freely moving rats," in Electrochemical Methods for Neuroscience, eds A. C. Michael and L. M. Borland (Boca Raton: CRC Press), 17-34.

Robinson, D. L., Zitzman, D. L., Smith, K. J., and Spear, L. P. (2011). Fast dopamine release events in the nucleus accumbens of early adolescent rats. Neuroscience 176, 296-307.

Rohitsingh, S. A., Smith, J. A., and Shair, H.N. (2011). Sex and experience influence behavioral responses of adult rats to potentiated and nonpotentiated ultrasonic vocalizations of pups. Dev. Psychobiol. PMID: 21432845. [Epub ahead of print].

Roitman, M. F., Stuber, G. D., Phillips, P. E., Wightman, R. M., and Carelli, R. M. (2004). Dopamine operates as a subsecond modulator of food seeking. J. Neurosci. 24, 1265-1271.

Rosenblatt, J.S. (1994). Psychobiology of maternal behavior: contribution to the clinical understanding of maternal behavior among humans. Acta Paediatr. Suppl. 397, 3-8.

Ross, S. B. (1991). Synaptic concentration of dopamine in the mouse striatum in relationship to the kinetic properties of the dopamine receptors and uptake mechanism. J. Neurochem. 56, 22-29.

Salamone, J.D., Correa, M., Farrar, A., and Mingote, S. M. (2007). Effort-related functions of nucleus accumbens dopamine and associated forebrain circuits. Psychopharmacology (Berl.) 191, 461-482.
Salamone, J. D., Correa, M., Mingote, S. M., and Weber, S. M. (2005). Beyond the reward hypothesis: alternative functions of nucleus accumbens dopamine. Curr. Opin. Pharmacol. 5, 34-41.

Scattoni, M. L., Crawley, J., and Ricceri, L. (2009). Ultrasonic vocalizations: a tool for behavioural phenotyping of mouse models of neurodevelopmental disorders. Neurosci. Biobehav. Rev. 33 , 508-515.

Schultz, W. (1998). Predictive reward signal of dopamine neurons. $J$. Neurophysiol. 80, 1-27.

Schultz, W. (2007). Multiple dopamine functions at different time courses. Annu. Rev. Neurosci. 30, 259-288.

Schultz, W., Dayan, P., and Montague, P. R. (1997). A neural substrate of prediction and reward. Science 275 1593-1599.

Shahrokh, D. K., Zhang, T. Y., Diorio, J., Gratton, A., and Meaney, M. J. (2010). Oxytocin-dopamine interactions mediate variations in maternal behavior in the rat. Endocrinology 151 , 2276-2286.

Sombers, L. A., Beyene, M., Carelli, R. M., and Wightman, R.M. (2009). Synaptic overflow of dopamine in the nucleus accumbens arises from neuronal activity in the ventral tegmental area. J. Neurosci. 29, 1735-1742.

Stolzenberg, D.S., and Numan, M. (2011) Hypothalamic interaction with the mesolimbic DA system in the control of the maternal and sexual behaviors in rats. Neurosci. Biobehav. Rev. 35 826-847.

Stuber, G. D., Hnasko, T. S., Britt, J. P., Edwards, R. H., and Bonci, A. (2010a). Dopaminergic terminals in the nucleus accumbens but not the dorsal striatum corelease glutamate. J. Neurosci. 30, 8229-8233.

Stuber, G. D., Hopf, F. W., Tye, K. M. Chen, B. T., and Bonci, A. (2010b). Neuroplastic alterations in the limbic system following cocaine or alcohol exposure. Curr. Top. Behav. Neurosci. 3, 3-27.

Stuber, G. D., Klanker, M., de Ridder, B. Bowers, M. S., Joosten, R. N., Feenstra M. G., and Bonci, A. (2008). Rewardpredictive cues enhance excitatory synaptic strength onto midbrain dopamine neurons. Science 321, 1690-1692.

Stuber, G. D., Roitman, M. F., Phillips, P. E., Carelli, R. M., and Wightman, R. M. (2005). Rapid dopamine signaling in the nucleus accumbens during contingent and noncontingent cocaine administration. Neuropsychopharmacology 30, 853-863.

Suaud-Chagny, M. F., Chergui, K., Chouvet, G., and Gonon, F. (1992)
Relationship between dopamine release in the rat nucleus accumbens and the discharge activity of dopaminergic neurons during local in vivo application of amino acids in the ventral tegmental area. Neuroscience 49, 63-72.

Suaud-Chagny, M. F., Dugast, C., Chergui, K., Msghina, M., and Gonon, F. (1995). Uptake of dopamine released by impulse flow in the rat mesolimbic and striatal systems in vivo. $J$. Neurochem. 65, 2603-2611.

Sulzer, D., and Rayport, S. (2000). Dale's principle and glutamate corelease from ventral midbrain dopamine neurons. Amino Acids 19, 45-52.

Takmakov, P., Zachek, M. K., Keithley, R. B., Bucher, E. S., McCarty, G. S., and Wightman, R. M. (2010). Characterization of local $\mathrm{pH}$ changes in brain using fast-scan cyclic voltammetry with carbon microelectrodes. Anal. Chem. 82, 9892-9900.

Tecuapetla, F., Patel, J. C., Xenias, H., English, D., Tadros, I., Shah, F., Berlin, J., Deisseroth, K., Rice, M. E., Tepper, J. M., and Koos, T. (2010). Glutamatergic signaling by mesolimbic dopamine neurons in the nucleus accumbens. J. Neurosci. 30, 7105-7110.

Tsai, H. C., Zhang, F., Adamantidis, A., Stuber, G. D., Bonci, A., de Lecea, L. and Deisseroth, K. (2009). Phasic firing in dopaminergic neurons is sufficient for behavioral conditioning. Science 324, 1080-1084.

Valenstein, E. S., Cox, V. C., and Kakolewski,J.W.(1968). Modification of motivated behavior elicited by electrical stimulation of the hypothalamus. Science 159, 1119-1121.

Venton, B. J., Michael, D. J., and Wightman, R. M. (2003). Correlation of local changes in extracellular oxygen and $\mathrm{pH}$ that accompany dopaminergic terminal activity in the rat caudateputamen. J. Neurochem. 84, 373-381.

Vickrey, T. L., Condron, B., and Venton, B. J. (2009). Detection of endogenous dopamine changes in Drosophila melanogaster using fast-scan cyclic voltammetry. Anal. Chem. 81, 9306-9313.

Wansaw, M. P., Pereira, M., and Morrell, J. I. (2008). Characterization of maternal motivation in thelactating rat: contrasts between early and late postpartum responses. Horm. Behav. 54, 294-301.

Watson, C. J., Venton, B. J., and Kennedy, R. T. (2006). In vivo measurements of neurotransmitters by microdialysis sampling. Anal. Chem. 78, 1391-1399.

Westerink, B. H. (1995). Brain microdialysis and its application for the study of animal behaviour. Behav. Brain Res. 70, 103-124.

Wickens, J. R., Horvitz, J. C., Costa, R. M., and Killcross, S. (2007). Dopaminergic 
mechanisms in actions and habits. J. Neurosci. 27, 8181-8183.

Wightman, R. M., Heien, M. L., Wassum, K. M., Sombers, L. A., Aragona, B. J., Khan, A.S., Ariansen, J. L., Cheer, J. F., Phillips, P.E., and Carelli, R. M. (2007). Dopamine release is heterogeneous within microenvironments of the rat nucleus accumbens. Eur. J. Neurosci. 26, 2046-2054.

Willuhn, I., Wanat, M. J., Clark, J. J., and Phillips, P.E. (2010). Dopamine signaling in the nucleus accumbens of animals self-administering drugs of abuse. Curr. Top. Behav. Neurosci. 3, 29-71.

Yang, H., and Michael, A. C. (2007).

"In vivo fast-scan cyclic voltamme- try of dopamine near microdialysis probes," in Electrochemical Methods for Neuroscience, eds A. C. Michael and L. M. Borland (Boca Raton: CRC Press), 489-501.

Yin, H.H., and Knowlton, B. J. (2006). The role of the basal ganglia in habit formation. Nat. Rev. Neurosci. 7, 464-476.

Zimmerberg, B., Kim, J.H., Davidson,A.N., and Rosenthal,A. J. (2003). Early deprivation alters the vocalization behavior of neonates directing maternal attention in a rat model of child neglect. Ann. N. Y. Acad. Sci. 1008, 308-313.

Zweifel, L. S., Parker, J. G., Lobb, C. J., Rainwater, A., Wall, V. Z., Fadok, J. P., Darvas, M., Kim, M. J., Mizumori, S.
J., Paladini, C. A., Phillips, P. E., and Palmiter, R. D. (2009). Disruption of NMDAR-dependent burst firing by dopamine neurons provides selective assessment of phasic dopaminedependent behavior. Proc. Natl. Acad. Sci. U.S.A. 106, 7281-7288.

Conflict of Interest Statement: The authors declare that the research was conducted in the absence of any commercial or financial relationships that could be construed as a potential conflict of interest.

Received: 01 March 2011; paper pending published: 21 March 2011; accepted: 23 April 2011; published online: 09 May 2011.
Citation: Robinson DL, Zitzman DL and Williams SK (2011) Mesolimbic dopamine transients in motivated behaviors: focus on maternal behavior. Front. Psychiatry 2:23. doi: 10.3389/fpsyt.2011.00023

This article was submitted to Frontiers in Child and Neurodevelopmental Psychiatry, a specialty of Frontiers in Psychiatry.

Copyright (C) 2011 Robinson, Zitzman and Williams. This is an open-access article subject to a non-exclusive license between the authors and Frontiers Media $S A$, which permits use, distribution and reproduction in other forums, provided the original authors and source are credited and other Frontiers conditions are complied with. 